\title{
DIAGNÓSTICO DO DESEMPENHO NA DOCÊNCIA DA GRADUAÇÃO DA UNISC
}

\author{
ANA KaRIN NunES* \\ Carmen LÚCia de Lima Helfer**
}

Recebido em: 16 de junho de 2008

Aprovado em: 06 de agosto de 2008

\begin{abstract}
* Assessora de Avaliação Institucional da UNISC - Universidade de Santa Cruz do Sul. Mestre em Comunicação Social pela PUCRS. Especialista em Gestão Universitária pela UNISC. Integrante do Grupo de Pesquisa "Avaliação e inovações em sinergia com tecnologias de informação" do PPG em Educação da UFRGS. E-mail: anunes@unisc.br

** Pró-Reitora de Graduação da UNISC - Universidade de Santa Cruz do Sul. Mestre em Educação pela PUCRS. Especialista em Gestão Universitária pelo CRUB. Especialista em Currículo por Atividades pela UNISC.E-mail: carmenh@unisc.br
\end{abstract}

Resumo: Na perspectiva de aperfeiçoar o seu processo de auto-avaliação, a Subcomissão de Avaliação da Graduação da UNISC promoveu, no ano de 2006, o Diagnóstico do Desempenho Docente na Graduação. Os objetivos do trabalho foram: identificar o conceito do "bom professor" para a comunidade docente e discente, explicitando como este conceito está sendo vivenciado nas práticas diárias do curso, e subsidiar a revisão dos instrumentos de avaliação do desempenho docente da Universidade. Este trabalho traz os principais resultados do processo, que contou com a participação de estudantes e docentes.

Palavras chave: Bom professor. Universidade. Avaliação. Graduação.

DIAGNOSIS OF TEACHER PERFORMANCE IN THE UNDERGRADUATE PROGRAMS AT UNISC

Abstract: Hoping to improve its self-evaluation process, the Sub-Commission for Graduation Undergraduate Teacher'S Evaluation of UNISC carried out, in 2006, the Diagnosis of Teaching Performance at Undergraduate Couses Graduation. The goals of this work were: to identify the concept of "good teacher" to teaching and learning community, showing how this process has been experienced through daily course practice, and supply the review for instruments of teaching performance evaluation at the University. This work brings up the main results of the process, which relied on the participation of students and teachers.

Key words: Good teacher. University. Evaluation. Graduation.

\section{Introdução}

A UNISC - Universidade de Santa Cruz do Sul já acumula mais de duas décadas de experiência com processos de auto-avaliação.

No ano de 2006, a UNISC foi uma das primeiras universidades do país a passar pela Avaliação Institucional Externa no âmbito do SINAES - Sistema Nacional de Avaliação da Educação Superior. 
Grande parte dessa experiência, a exemplo do que acontece com a grande maioria das instituições de educação superior do país, está situada na avaliação de indicadores relativos ao desempenho dos professores e das disciplinas no contexto dos cursos de graduação.

Ao longo de toda a sua trajetória, a Universidade sempre procurou desenvolver a avaliação de professores, disciplinas e cursos em parceria com a comunidade acadêmica, acolhendo sugestões que tinham por objetivo a melhoria de todo o processo. Também contou com o olhar de especialistas externos que tiveram a oportunidade de conhecer e emitir juízos de valor sobre as atividades desenvolvidas.

No ano de 2007, quando a Universidade iniciou o planejamento da quarta fase do seu Programa de Avaliação Institucional - PAIUNISC IV ${ }^{1}$, a Subcomissão de Avaliação da Graduação ${ }^{2}$, na tentativa de valorizar ainda mais a função educativa da avaliação dentro da Universidade, propôs o Diagnóstico do Desempenho Docente.

Os objetivos do Diagnóstico foram:

a) identificar o conceito do "bom professor" para a comunidade docente e discente, explicitando como este conceito está sendo vivenciado nas práticas diárias do curso;

b) subsidiar a revisão dos instrumentos de avaliação do desempenho docente da Universidade.

Dentro da perspectiva de uma avaliação formativa, onde tão significativa quanto a avaliação das particularidades é a avaliação do processo de ensinoaprendizagem, o Diagnóstico do Desempenho Docente gerou subsídios ainda mais consistentes para o aperfeiçoamento dos mecanismos auto-avaliativos.

Esse trabalho tem por objetivo apresentar os resultados desse processo de Diagnóstico que contou com a participação dos estudantes e professores da Universidade.

1 O documento que norteia as práticas avaliativas da Universidade é o PAIUNISC - Programa de Avaliação Institucional da UNISC. O Programa é planejado em fases, situadas em um espaço temporal. A primeira fase data do período de 1994 a 1995. Atualmente planeja-se a quarta fase: 2008-2012.

2 Para a operacionalização de seus processos de avaliação nas dez dimensões previstas pelo Sistema Nacional de Avaliação da Educação Superior - SINAES, a Universidade de Santa Cruz do Sul conta seis Subcomissões. Atualmente elas estão assim divididas: graduação, pós-graduação lato sensu, pós-graduação stricto sensu, pesquisa, extensão e gestão. A Subcomissão de Avaliação da Graduação é nomeada pelo Conselho de Graduação, observando-se a seguinte composição: Pró-Reitor de Graduação - que tem a atribuição de coordenador da subcomissão, um chefe de departamento, três coordenadores de curso de graduação, Coordenador de Graduação da Pró-Reitoria de Graduação, Coordenador Pedagógico da Pró-Reitoria de Graduação, Assessor Pedagógico da Pró-Reitoria de Graduação, dois representantes do Núcleo de Avaliação da Graduação, Assessor de Avaliação Institucional da Pró-Reitoria de Planejamento e um representante do corpo discente. 


\section{Bases Teóricas}

O SINAES, instituído pela Lei n ${ }^{\circ} 10.861$, de 14 de abril de 2004, trouxe uma nova perspectiva a respeito da função da avaliação para o sistema educacional. Construída a partir do trabalho da Comissão Especial de Avaliação - CEA, a proposta explicita o caráter educativo que os processos avaliativos devem preservar, com objetivos essencialmente formativos, para que possam gerar a melhoria da qualidade acadêmica em todos os níveis.

Ristoff $(1999$, p. 58), diz que "há na avaliação uma função educativa que, em muito, sobrepuja no mérito a dualidade do crime e do castigo". O processo avaliativo tem a função de (a) firmar valores, daí não existir neutralidade em um instrumento de avaliação, seja ele científico-técnico, didático-pedagógico, atitudinal. Eles são sempre resultados de concepções valorativas que a universidade já possui, ou quer ver instaladas em dado momento de sua trajetória. Os usos que se pode fazer da avaliação são inúmeros e, portanto, seria inconveniente atrelá-los a princípios de punição ou premiação já que não se inscrevem no vazio de um processo, mas em uma realidade cercada por valores e concepções já alicerçados. A ênfase na função educativa da avaliação e o reconhecimento do seu viés não-punitivo não significa que a avaliação restrinja-se a uma constatação da situação dada, sem efeito prático. A avaliação sem conseqüências é estéril e leva ao próprio esgotamento. Os processos avaliativos devem ser acompanhados por providências efetivas, de modo a extrair das constatações sobre a situação vigente o seu potencial transformador. Como dito por Ribeiro (2004, p. 15), a avaliação "não deve ter um sentido punitivo em seu cerne, mas deve trazer resultados que se expressem em termos de incentivos e de advertências, adequados a cada caso".

Quanto à sua função formativa, a avaliação deve ser utilizada para a melhoria e o desenvolvimento de uma determinada atividade ou programa. Além dos levantamentos, descrições e interpretações de indicadores, deve propiciar diagnósticos consistentes que possibilitem a formação de juízos de valor e a concretização de ações efetivas.

No entanto, embora haja consenso a respeito do caráter formativo da avaliação institucional, Rodrigues (2006, p. 151) salienta que, finalizadas as etapas de diagnóstico do processo, normalmente os responsáveis pela sua condução são tomados por uma certa "apatia". Isso porque "seja da avaliação dos professores pelos alunos, seja da avaliação da instituição pelos docentes, seja de qualquer outra sistematização avaliativa, os protagonistas, em geral, não chegam à fase de intervenções.” 
Tomando a questão específica da avaliação do desempenho docente, essa "apatia" citada pelo autor evidencia-se ainda mais quando são tomados como exemplos os casos de instituições que se dedicam por anos na condução de processos sistemáticos de consulta à opinião de alunos e professores, gerando nada mais do que uma infinidade de dados sem uso prático.

A avaliação, além de ter como objetivo o aprimoramento da prática docente, tem ainda, conforme ressalta Rasco (2000), uma função em relação ao processo direto de formação docente, pois revela a "pedagogia” e os "valores" do corpo de professores de uma instituição.

Quando me refiro à pedagogia, estou pensando em questões como estratégias docentes, as formas de relação com o alunado e o conhecimento, a sensibilidade e a adaptabilidade das mesmas questões parecidas; e quando me refiro aos valores docentes, faço-o pensando na contribuição ao conhecimento cultural e científico da docência, à compreensão e sensibilidade pelas injustiças sociais e econômicas que nos oprimem, ao caráter democrático da instituição universitária e de nossas relações educativas, às responsabilidades morais e de cidadania que fomentemos em nossas aulas. A auto-avaliação institucional está obrigada a mostrar tudo isso, a fazer-nos partícipes desta complexa ecologia docente; porém, mudar nossa pedagogia e ainda mais nossos valores não lhe pertence. (p. 91)

Dentro desta perspectiva, a avaliação institucional deve despertar os professores para a revisão de suas práticas e condutas, assim como nortear as políticas dos programas de formação continuada.

No entanto, tão importante quanto definir os objetivos e funções da avaliação do desempenho docente é também definir os critérios sobre os quais essa avaliação irá desenvolver-se. Isso significa que a instituição precisa construir coletivamente, com base nos seus valores e compromissos, alguns parâmetros mínimos que norteiem o processo.

Esses parâmetros estão diretamente associados à idéia do que alguns autores, como Cunha (1989), denominam como o "bom professor”. Ou seja, são indissociáveis ao conceito que a instituição, seus alunos e o próprio corpo docente compactuam como os aspectos desejáveis no desempenho de um professor.

Ainda na visão de Cunha (1989), o "bom professor" é aquele que "deu certo". Embora esse conceito seja variável entre as pessoas, visto que contém a expressão de um valor, a autora sugere que aquele professor que melhor responder às necessidades do aluno e da instituição em dado momento terá maior probabilidade de ser considerado o melhor. Em seu estudo, a pesqui- 
sadora explicita ainda que as habilidades de ensino manifestadas pelo "bom professor” podem ser reunidas em cinco grupos: organização do contexto da aula, incentivo à participação do aluno, trato da matéria de ensino, variação de estímulo e uso da linguagem.

Grillo (2001, p. 78) diz que a docência envolve o professor em sua totalidade: "sua prática é resultado do saber, do fazer e principalmente do ser, significando um compromisso consigo mesmo, com o aluno, com o conhecimento e com a sociedade e sua transformação". Com isso, tem-se que a prática docente pode ser estudada sob a ótica da dimensão pessoal, da dimensão prática, da dimensão conhecimento profissional e da dimensão contextual.

O ponto inicial para a análise das dimensões da docência está na figura do professor como pessoa e profissional, ou seja, na dimensão pessoal. A relação que ele estabelece com o aluno tem um caráter de reciprocidade e marca o clima vivido na classe. Traduz, implicitamente, o entendimento que aluno e professor têm dessa relação.

A dimensão prática, segundo Grillo (2001) diz respeito às direções que o professor imprime ao seu fazer docente dentro de um cenário marcado pela complexidade e pela contradição. Envolve as suas habilidades técnicas no desenvolvimento de suas ações, assim como a sua capacidade de articular saberes formalizados e saberes da experiência.

A dimensão do conhecimento profissional docente envolve diferentes tipos de conhecimentos articulados de forma idiossincrática que ultrapassam o conhecimento de especialistas numa área ou mesmo o conhecimento resultante da experiência. Origina-se de vários eixos: do eixo científico do conhecimento profissional, do eixo psicopedagógico, do eixo empírico do conhecimento.

Por sua vez, a dimensão contextual diz respeito a uma prática docente aberta para a realidade, com um ensino interativo, reunindo novas áreas e novos contextos, criando um cenário pedagógico mais rico e amplo.

Com base nesses conceitos, pode-se dizer que a avaliação do desempenho docente deve levar em conta todas as dimensões da prática docente. De igual maneira, também deve ser balizada por aquilo que a instituição e os seus sujeitos compactuam como conceito de um “bom professor”. São essas referências que irão nortear, além de políticas institucionais, questões mais técnicas que vão da construção de instrumentos de coleta de dados à responsabilização dos envolvidos em relação às informações obtidas.

Talvez, considerando esses pressupostos teóricos, construídos a partir de investigações da prática de avaliação da docência em contextos universitários, as instituições de educação superior possam garantir processos mais legítimos, 
no sentido de se apresentarem com credibilidade e ética perante a comunidade acadêmica. De igual maneira, também se pode prever um processo mais justo, partindo-se da premissa de que seja oportunizada a participação de todos na construção das suas diretrizes.

\section{Metodologia de Aplicação da Proposta}

$\mathrm{Na}$ primeira fase do trabalho que se referia à construção do conceito do "bom professor", todos os coordenadores dos cursos de graduação da UNISC realizaram um debate com alunos e professores, separadamente, a fim de coletar os dados necessários ao diagnóstico.

O Roteiro de Diagnóstico do Desempenho Docente previu a condução do debate a partir de dois eixos. Inicialmente os alunos e professores atribuíam um grau de importância, a partir de indicadores pré-definidos, aos aspectos que estão presentes no seu conceito de um "bom professor”. Em seguida, os alunos e professores indicaram a sua satisfação em relação ao desempenho docente, de modo geral, em seu curso.

Cada coordenador recebeu, da Subcomissão de Avaliação da Graduação, um "kit” com todos os documentos necessários para a aplicação da proposta.

Entre os documentos, estava o Roteiro de Entrevista. O Roteiro era dividido em três partes. Na primeira parte, estudantes e professores tinham que atribuir um grau de importância aos indicadores, a partir da referência que tinham do que é um "bom professor”. A Subcomissão de Graduação sugeriu 14 indicadores, construídos a partir dos estudos citados e de instrumentos de avaliação aplicados pela Universidade. No entanto, esses indicadores podiam ser alterados, substituídos ou acrescidos com as propostas que o grupo julgasse mais pertinentes. $\mathrm{Na}$ segunda parte do Roteiro, estudantes e professores tinham que indicar o seu grau de satisfação, com relação aos indicadores consolidados na primeira parte do instrumento, de acordo com a prática docente de seu curso de graduação. A terceira parte do instrumento era aberta à livre manifestação do grupo.

\section{1를 ETAPA - Debate com os estudantes}

Os coordenadores de curso escolheram data e horário para a aplicação do Roteiro dentro de algumas opções pré-determinadas pela Subcomissão de Avaliação da Graduação tendo em vista os dias de maior concentração de estudantes no campus. 
Após a escolha da data e a definição do horário pelos cursos, a Subcomissão de Avaliação da Graduação providenciou uma lista dos alunos que compuseram a amostra.

A respeito da composição da amostra, a literatura referente à pesquisa qualitativa não é consensual em relação à definição do seu tamanho neste tipo de estudo. Ao mesmo tempo em que uma corrente de autores defende que não há necessidade de definição de um número mínimo de sujeitos a serem ouvidos em uma pesquisa qualitativa, outra corrente argumenta que essa definição é importante para que os resultados não sejam comprometidos ou contra-argumentados.

Tendo em vista as características da população a ser pesquisada, a Subcomissão de Avaliação da Graduação entendeu que alguns parâmetros mínimos na composição da amostra fazem-se necessários pelos seguintes motivos:

a) o tamanho da população era conhecido;

b) quanto mais representativa a amostra, mais facilmente poderiam ser feitas generalizações;

c) a pesquisa é institucional, no entanto também pretendia verificar dados por áreas do conhecimento e até por cursos;

d) a definição amostral facilitaria o trabalho de operacionalização da proposta.

Nesse sentido, as diretrizes para a composição das amostras foram as seguintes:

a) as amostras, por curso/turno/campi, foram compostas por um número mínimo de 20 estudantes, sorteados previamente: com isso, objetivouse alcançar uma representatividade total de $10 \%$ do corpo docente da Instituição;

b) $25 \%$ da amostra (5 estudantes) deveria ser composta por estudantes que tivessem concluído entre $7 \%$ e $22 \%$ dos créditos do seu curso, $50 \%$ da amostra (10 estudantes) por estudantes que tenham concluído entre $23 \%$ e $79 \%$ dos créditos do seu curso, 25\% da amostra (5 estudantes) por estudantes que tenham concluído mais de $80 \%$ dos créditos do seu curso: com esses critérios, que são idênticos àqueles utilizados pelo Exame Nacional de Desempenho dos Estudantes - ENADE, pretendiase garantir mais heterogeneidade.

Ocorreram casos de cursos que não se enquadraram em todos os parâmetros. Essas particularidades foram avaliadas no sentido de se buscar a maior aproximação possível às características amostrais propostas. 
A Subcomissão de Avaliação da Graduação forneceu aos coordenadores uma lista nominal dos estudantes, com os quais foi feito o debate, a partir dos critérios citados acima. Essa lista tinha o nome de 20 alunos matriculados no dia e horário do debate.

Para cada um dos nomes da lista foi sorteado ainda um suplente. Ou seja, caso um dos estudantes da primeira lista não estivesse na Universidade no dia do debate, poderia ser substituído por outro com as mesmas características determinadas para a composição da amostra. Caso nenhum dos dois estudantes estivesse presente, as faltas deveriam ser registradas em formulário próprio.

Os estudantes que quisessem participar voluntariamente do processo, poderiam fazê-lo mediante registro na lista de presença.

Foi sugerido aos coordenadores de curso que conversassem com todos os estudantes do curso sobre o trabalho de Diagnóstico. A Subcomissão de Avaliação da Graduação auxiliou na sensibilização utilizando-se de instrumentos como listas de e-mails e material impresso.

Cada coordenador buscou ainda, junto ao Diretório Acadêmico do Curso ou aos representantes de turma, um estudante que o auxiliou na aplicação da proposta.

Os Roteiros, após a aplicação, devidamente preenchidos, foram remetidos à Subcomissão de Avaliação da Graduação em conjunto com a lista de presença assinada pelos alunos.

\section{2를 ETAPA - Debate com os professores}

Os coordenadores foram orientados a reunir o máximo de professores que tenham lecionado no Curso durante o semestre. Portanto, na etapa com os docentes, não foi estabelecido um número mínimo para a amostra.

A presença dos professores foi registrada em formulário próprio e encaminhada à Subcomissão de Avaliação da Graduação.

Os coordenadores de curso foram auxiliados pelos seus respectivos subcoordenadores na aplicação do Roteiro.

Também foi sugerido que os coordenadores conversassem com todos os professores do curso sobre o Diagnóstico, pois era fundamental que todos compreendessem o seu papel para a construção de um processo educativo, participativo e ético.

As orientações para aplicação do roteiro, o material disponibilizado para a condução da proposta e a coleta e sistematização dos dados seguiram as mesmas diretrizes da etapa realizada com os estudantes. 


\section{Análise dos Resultados}

Para a análise dos resultados, a Assessoria de Avaliação Institucional ${ }^{3}$ fez a sistematização de todos os dados levantados a partir dos cursos. De posse dos relatórios, a Subcomissão de Avaliação da Graduação dividiu-se ainda em pequenos grupos, responsáveis pela análise qualitativa dos resultados com vistas à formulação do conceito do "bom professor" e pela revisão dos indicadores propostos para a avaliação do desempenho docente.

Para algumas análises foram utilizados cortes a partir das grandes áreas do conhecimento, a saber:

1. Ciências Biológicas e Saúde - concentra os cursos de: Ciências Biológicas, Educação Física, Enfermagem, Farmácia, Fisioterapia, Medicina, Nutrição, Odontologia, Psicologia;

2. Ciências Exatas e Engenharias - concentra os cursos de: Arquitetura e Urbanismo, Ciência da Computação, Engenharia Agrícola, Engenharia Ambiental, Engenharia de Computação, Engenharia de Produção, Matemática, Química Industrial, Sistemas de Informação;

3. Ciências Humanas e Licenciaturas - concentra os cursos de: Ciências Sociais, Filosofia, Geografia, História, Letras, Licenciatura em Computação, Pedagogia, Serviço Social;

4. Ciências Sociais Aplicadas - concentra os cursos de: Administração, Automação de Escritórios e Secretariado, Ciências Contábeis, Ciências Econômicas, Comunicação Social, Direito, Tecnólogo em Assistência e Segurança Prisional, Turismo.

O trabalho da Assessoria de Avaliação Institucional e dos grupos de trabalho resultou em um Relatório que foi colocado para apreciação da Subcomissão de Avaliação da Graduação. A partir desse Relatório foram desencadeadas as estratégias de socialização dos resultados com a comunidade acadêmica, especialmente com coordenadores de curso, professores e estudantes que se fizeram presentes nas reuniões do Diagnóstico do Desempenho Docente 2006.

Com relação à participação dos estudantes no processo de Diagnóstico, 12\% do total de matriculados na Instituição no período participaram dos debates. Esse índice ultrapassou a estimativa inicial da Subcomissão que era de 10\%

3 Órgão ligado à Pró-Reitoria de Planejamento, que coordena e dá suporte aos processos de auto-avaliação da Universidade. 
do total de matriculados. Vale observar ainda que, do total de participantes, 7\% apresentaram-se de forma voluntária, ou seja, mesmo não-sorteados para fazer parte da amostra, fizeram-se presentes no processo. No que se refere ao corpo docente, 45\% participaram do Diagnóstico. Esse número foi considerado bom pela Subcomissão.

\section{Conceito do "bom professor"}

Grillo (2001, p. 78), considera que "a docência envolve o professor em sua totalidade; sua prática é resultado do saber, do fazer e principalmente do ser, significando um compromisso consigo mesmo, com o aluno, com o conhecimento e com a sociedade e sua transformação". Com isso, propõe que a docência seja estudada sob a ótica de quatro dimensões, distintas, mas relacionadas:

1. Dimensão pessoal: envolve a identidade do professor, sua maneira de se relacionar com o grupo. Se expressa de forma mais concreta na relação professor-aluno, acentuando a responsabilidade ética do professor;

2. Dimensão prática: diz respeito às direções que o professor imprime no seu fazer docente. Se expressa nas habilidade técnicas no desenvolvimento de ações complexas como organizar situações de aprendizagem, formular exemplos, responder a questões;

3. Dimensão conhecimento profissional: refere-se ao conhecimento necessário ao professor para realizar o ensino. Origina-se dos seguintes eixos: científico, psicopedagógico, empírico, prática particular sustentada pela reflexão crítica;

4. Dimensão contextual: trata da capacidade de trazer para o espaço da sala de aula a realidade contextual, ou mesmo de deixar a sala de aula e ir até a comunidade. $O$ professor assume responsavelmente a tarefa educativa, aprofundando temas e encorajando a formação cidadã.

No estudo intitulado O bom professor e sua prática, Cunha (1999), apreendeu dados sobre o que faz um "bom professor" no seu cotidiano escolar:

a) os alunos esperam que o bom professor seja hábil no falar e permita intervenções quando necessário; 
b) os bons professores manifestam habilidades em sala de aula: organização do contexto da aula, incentivo à participação do aluno, trato da matéria de ensino, variação de estímulo e uso da linguagem.

O instrumento proposto para o Diagnóstico do Desempenho Docente contemplou a seguinte questão e indicadores:

Questão: Qual a importância que os fatores abaixo têm para os estudantes/professores do curso com referência ao conceito que possuem sobre o que é um "bom professor"?

a) apresentar clareza ao comunicar o conteúdo;

b) ser pontual (no início da aula, no retorno do intervalo e no fim da aula);

c) demonstrar interesse e cooperação na aprendizagem do estudante;

d) demonstrar disponibilidade de ouvir, compreender os questionamentos do estudante;

e) desenvolver o plano da disciplina;

f) demonstrar preparação das aulas;

g) indicar material impresso e/ou referências disponíveis na Biblioteca;

h) utilizar o Ambiente EAD (Educação a Distância) como apoio ao ensino presencial;

i) utilizar variadas técnicas de ensino (ex: aula expositiva, trabalhos em grupo ou individualizados, debates etc.) e recursos didáticos (ex: retroprojetor, multimídia, vídeos, quadro etc.) tornando a aula atrativa e facilitadora da aprendizagem;

j) aplicar instrumentos de avaliação (ex: provas, seminários, trabalhos etc.) correspondentes aos conhecimentos do conteúdo trabalhado em aula;

k) retomar e discutir com a turma os conteúdos/habilidades não entendidos, utilizando a avaliação como processo de construção da aprendizagem;

4 Foram dadas as seguintes opções de resposta aos indicadores: muito importante, importante, indiferente, pouco importante, nada importante. $\mathrm{O}$ instrumento dispunha ainda de espaço para inclusão de novos indicadores ou mesmo exclusão ou readequação dos indicadores. 
1) articular o conteúdo com a formação geral e/ou profissional do estudante;

m) evidenciar conhecimento do conteúdo da disciplina;

n) relacionar o conteúdo com a realidade contextual (social, científica, tecnológica, política, econômica).

A análise dos resultados do Diagnóstico do Desempenho Docente da Graduação da UNISC revelou que estudantes e professores da Universidade consideram como o fator mais importante no conceito que têm formulado sobre o "bom professor" o conhecimento do conteúdo da disciplina. Os estudantes enfatizaram ainda que o "bom professor" deve apresentar clareza ao comunicar o conteúdo. Já os professores destacaram a capacidade de articular o conteúdo com a formação geral e/ou profissional, como um indicador importante à prática docente.

Questões como a utilização do ambiente de educação a distância como apoio ao ensino presencial, utilização de variadas técnicas de ensino em sala de aula e pontualidade foram apontadas como tendo pouca importância para o conceito do "bom professor". Especialmente com relação à questão da pontualidade, os estudantes destacaram que o importante é que o docente saiba aproveitar bem o tempo disponível na sala de aula.

As análises a partir das quatro áreas do conhecimento revelaram que há uma certa convergência na caracterização do "bom professor”. No entanto, foram percebidas algumas singularidades.

Os estudantes das quatro áreas do conhecimento apontam que os indicadores relativos à preparação das aulas, à clareza ao comunicar o conteúdo e ao conhecimento do conteúdo da disciplina têm grau máximo de importância no conceito do "bom professor". Os acadêmicos das áreas de Ciências Humanas e Licenciaturas e Ciências Sociais Aplicadas destacaram ainda que o professor deve demonstrar disponibilidade de ouvir os alunos e compreender seus questionamentos.

Os professores das quatro áreas do conhecimento também foram unânimes ao atribuir grau máximo de importância ao indicador de que o "bom professor" deve evidenciar conhecimento do conteúdo da disciplina. As áreas de Ciências Sociais Aplicadas e de Ciências Exatas e Engenharias enfatizaram ainda que a boa prática docente deve articular o conteúdo com a formação geral e/ou profissional do estudante. 
Outro recorte utilizado durante as análises foi o agrupamento dos indicadores que traduzem o conceito do "bom professor" nas dimensões propostas por Grillo (2001). Através desses dados verificou-se que as dimensões do conhecimento profissional e contextual são as que têm mais peso na idéia da boa prática docente.

Tendo em vista o grau de importância atribuído pelos estudantes e professores aos indicadores de avaliação, as sugestões deixadas na parte "aberta" do instrumento e o estudo das dimensões que compõem o "bom professor", a Subcomissão de Avaliação da Graduação trabalhou na reelaboração dos indicadores que refletem a boa prática docente na UNISC.

Ressalta-se que este trabalho foi fruto de uma análise detalhada de todas as sugestões encaminhadas por estudantes e professores durante o processo de Diagnóstico do Desempenho Docente. Nesse sentido, privilegiaram-se as questões mais recorrentes, ou seja, aquelas que eram compartilhadas na opinião de boa parte dos cursos.

O papel da Subcomissão de Avaliação da Graduação foi de sistematizar idéias e conceitos e traduzi-las em um instrumento que reflita o que se espera da prática docente na UNISC. O objetivo inicialmente proposto pelo Diagnóstico, qual seja a identificação do conceito do "bom professor" na Universidade, não foi abandonado. No entanto, compreendeu-se que a identificação desse conceito depende ainda de verificações sistemáticas dos indicadores propostos pelos estudantes e professores como reveladores da boa prática docente.

A Subcomissão julgou pertinente, além de propor os indicadores, categorizálos de acordo com as quatro dimensões que caracterizam a docência: dimensão pessoal, dimensão do conhecimento profissional, dimensão prática/técnica e dimensão contextual.

Esse exercício de categorização dos indicadores a partir das quatro dimensões revelou que um único indicador pode ser resultado de um conjunto de fatores que podem dizer respeito a mais de uma dimensão. Ou seja, a categorização não é estanque.

Com relação às dimensões envolvidas na prática docente, vale destacar ainda que, apesar de estudantes e professores terem atribuído um maior peso às dimensões do conhecimento profissional e contextual, não houveram indicativos no sentido de ampliar o número de questões nessas dimensões.

Sendo assim, a Subcomissão de Avaliação da Graduação propôs um conjunto de indicadores que traduzem o que os estudantes e professores da UNISC pensam a respeito do "bom professor". Esses indicadores passaram a ser utilizados na avaliação individual dos professores a partir do ano de 2007. 


\begin{tabular}{|c|c|c|}
\hline \multicolumn{3}{|c|}{$O(A)$ professor(a): } \\
\hline 1. & Demonstra respeito com os alunos & \multirow{3}{*}{ DIMENSÃO PESSOAL } \\
\hline & $\begin{array}{l}\text { Demonstrar interesse e cooperação na aprendizagem do } \\
\text { estudante, valorizando os seus questionamentos }\end{array}$ & \\
\hline 3. & É claro e preciso na comunicação do conteúdo & \\
\hline & $\begin{array}{l}\text { Demonstra conhecimento do conteúdo da disciplina/ } \\
\text { área }\end{array}$ & \multirow{2}{*}{$\begin{array}{l}\text { DIMENSÃO DO } \\
\text { CONHECIMENTO } \\
\text { PROFISSIONAL }\end{array}$} \\
\hline & $\begin{array}{l}\text { Amplia o conteúdo da disciplina, ilustrando as aulas com } \\
\text { resultados de pesquisa e/ou experiências profissionais }\end{array}$ & \\
\hline & Demonstra planejamento das aulas & \multirow{6}{*}{$\begin{array}{l}\text { DIMENSÃO PRÁTICA } \\
\text { TÉCNICA }\end{array}$} \\
\hline & $\begin{array}{l}\text { Utiliza metodologias, técnicas e recursos compatíveis com } \\
\text { os objetivos de ensino aprendizagem }\end{array}$ & \\
\hline & Aproveita adequadamente o tempo da aula & \\
\hline & $\begin{array}{l}\text { Indica a busca de material impresso, referências disponí- } \\
\text { veis na Biblioteca e outras fontes de pesquisa }\end{array}$ & \\
\hline & $\begin{array}{l}\text { Aplica instrumentos de avaliação (ex: provas, seminários, } \\
\text { trabalhos etc.) correspondentes aos conhecimentos de- } \\
\text { senvolvidos na disciplina/área }\end{array}$ & \\
\hline 11. & Retoma e discute os resultados das avaliações & \\
\hline & $\begin{array}{l}\text { Articula o conteúdo da disciplina com a formação geral } \\
\text { e/ou profissional do estudante }\end{array}$ & \multirow{2}{*}{$\begin{array}{l}\text { DIMENSÃO } \\
\text { CONTEXTUAL }\end{array}$} \\
\hline & $\begin{array}{l}\text { Estimula a reflexão e crítica sobre os aspectos sociais, } \\
\text { e/ou científicos, e/ou tecnológicos, e/ou políticos, e/ou } \\
\text { econômicos }\end{array}$ & \\
\hline
\end{tabular}

Quadro - Indicadores de avaliação individual dos professores, construídos após o Diagnóstico

\section{Considerações Finais}

O Diagnóstico do Desempenho Docente na graduação da UNISC constituiuse de um momento singular no que se refere à busca pelo aperfeiçoamento da prática docente institucional.

Entre os coordenadores de curso, estudantes e professores, o Diagnóstico possibilitou um espaço de diálogo e interação. Os registros dos debates deram conta de que todos se sentiram parte de uma construção coletiva, baseada em princípios éticos. Foram recebidas várias sugestões no sentido de instituir, de forma sistemática, essa prática na Instituição.

À Subcomissão de Avaliação da Graduação ficou evidente que a identificação do conceito do "bom professor" da UNISC ainda carece de outros dados. Os resultados oriundos da aplicação dos indicadores construídos a partir do Diagnóstico podem desvelar outras questões. Portanto, concluiu-se que seria 
prematuro definir um conceito a partir do trabalho realizado no ano de 2006. Embora estudantes e professores tenham apontado para algumas questões consensuais a respeito do que esperam da prática docente, há que se reconhecer a complexidade de traduzir essa questão em um conceito acabado.

Um outro trabalho de avaliação iniciado pela Pró-Reitoria de Graduação no ano de 2006, intitulado Diagnóstico da Graduação também deve trazer elementos novos à discussão da prática docente na UNISC.

Analisando-se os dois objetivos inicialmente propostos pelo Diagnóstico, quais sejam a identificação do conceito do "bom professor" da UNISC e a revisão do instrumento de avaliação do desempenho dos professores da Universidade, conclui-se que o primeiro foi parcialmente atendido, pois ainda depende de novas leituras. Já a proposição de indicadores para a avaliação individual dos professores foi contemplada.

\section{Referências}

CUNHA, Maria Isabel da. O bom professor e sua prática. 9. ed. São Paulo: Papirus, 1989.

GRILLO, Marlene. O professor e a docência: o encontro com o aluno. In: ENRICONE, Délcia (Org.). Ser professor. 2. ed. Porto Alegre: EDIPUCRS, 2001. p. 73-89.

RASCO, J. Félix Ângulo. A auto-avaliação institucional como processo de formação do professorado. In: DIAS SOBRINHO, J.; RISTOFF, D. I. Universidade desconstruída: avaliação institucional e resistência. Florianópolis: Insular, 2000. p. 73-94.

RIBEIRO, Renato Janine. O sentido democrático da avaliação. Cadernos do MEC, Brasília, p. 10-15, jun. 2004.

RISTOFF, Dilvo Ilvo. Universidade em foco: reflexões sobre a educação superior. Florianópolis: Insular, 1999.

RODRIGUES, Francisco de Paula Marques et al. O processo de avaliação institucional como multiplicador de iniciativas para o aperfeiçoamento docente $-1^{\text {a }}$ parte. Avaliação, Campinas; Sorocaba, ano 11, v. 11, p. 151-166, jun. 2006. 